This is an author-produced PDF of an article accepted for publication in Music Education Research. The definitive publisher-authenticated version is available online at: DOI: 10.1080/14613808.2013.824954. Copyright Taylor \& Frances.

Complete citation information of that definitive version is: Carey, G., Bridgstock, R., McWilliam, E., \& Taylor, P. \& Grant, C. (2013). Characterising one-to-one conservatoire teaching: Some implications of a quantitative analysis. Music Education Research (online version). doi: 10.1080/14613808.2013.824954

\title{
Characterising one-to-one conservatoire teaching: Some implications of a quantitative analysis
}

\author{
Gemma Carey, Ruth Bridgstock, Peter Taylor, Erica McWilliam, Catherine \\ Grant
}

\begin{abstract}
Despite the significant recent growth in research relating to instrumental, vocal and composition tuition in higher education, little is known about the diversity of approaches that characterise one-to-one teaching in the Conservatoire, and what counts as optimal practice for educating $21^{\text {st }}$-century musicians. Through analysis of video-recorded one-to-one lessons that draws on a 'bottom up' methodology for characterising pedagogical practices (Taylor, 2012; Taylor et al, 2012), this paper provides empirical evidence about the nature of one-to-one pedagogy in one Australian institution. The research aims (1) to enable a better understanding of current one-to-one conservatoire teaching; and (2) to build and improve upon existing teaching practice using authentic insights gained through systematic investigation. The authors hope the research will lead to a better understanding of the diversity and efficacy of the pedagogical practice within the specific context in which the study was conducted, and beyond, to Conservatoire pedagogy generally.
\end{abstract}

Keywords: one-to-one teaching; tertiary music education; music pedagogy; quantitative approach; instrumental and vocal teaching; teaching and learning

\section{Background}

Much of the literature conveys an overwhelming sense that one-to-one teaching plays a valuable, even irreplaceable, role in the training of professional musicians. Individual lessons are generally universally viewed as an 'indispensable, intense and intricate' part of instrumental and vocal learning (Gaunt, 2007, p. 230), and they are the clear pedagogical model of preference for delivering a 'serious' vocal and instrumental music education (Harrison, 2004, p. 4). Tertiary institutions display considerable respect for this model, promoting its existence as an 'internationally recognized' standard of teaching, one that needs to be 'safeguarded' for a country to remain musically competitive on the international scale (Harrison, 1997). Perhaps as a result, one-to-one pedagogy still serves as the primary method by which performance students in higher music education receive their practical skills and performance-based training (Association of European Conservatoires, 2010).

Criticism of the quality of one-to-one practices within conservatoires is not uncommon, however (e.g. Burwell, 2005; Carey, 2008; Froehlich, 2002; Kennell, 1997; Persson, 1996; Presland, 2005; Schmidt, 1989). Some studies suggest that this pedagogic model can have a negative impact on students (Burwell, 2005; Persson, 
1994), that the development of musical skills can be erratic, and that the learning that occurs in the one-to-one environment remains highly contextualised rather than producing adaptable and generalizable learning benefits (Mills, 2002). Rather than being grounded in the latest pedagogical understandings, teaching practices are often 'regulated through dominant norms and expectations in the educational community ... with certain rules, standards, and expectations related to what it means to be a teacher or a student in this particular educational context' (Nerland, 2007, p. 400). Gaunt (2009) draws attention to the lack of formal accreditation or generally agreed standards of good practice specifically in one-to-one teaching. The outcomes of the 'Polifonia' Working Group for Instrumental and Vocal Teacher Training in Europe (2007-2010) underscored a multitude of approaches to one-to-one pedagogy, and called for increased dialogue and collaboration on the issue at all levels, from the local to the international (Lennon \& Reed, 2012). More recently still, however, Perkins (2013) reflected on the 'largely unresearched and, crucially, relatively unchallenged' nature of conservatoire education.

Aside from these concerns, one-to-one is a costly model at a time when music institutions are struggling with the challenge of diminishing government funding, as well as institutional amalgamations and internal restructures (Lockett, 2008, p. 1). A combination of increasing student numbers, increasing student diversity, national and international benchmarking of trends and practices, and other curriculum pressures (such as the need to provide students with the skills to cope with a fast-changing music industry) has some commentators suggesting that the one-to-one model is left 'hanging in the balance' (Merson, 2012, p. 13). Currently, then, one-to-one teaching is being called to account.

\section{The study}

By analysing video-recordings of one-to-one lessons, employing a system for describing pedagogical elements, and theorising these elements in terms of the extant literature and the views of current stakeholders, this research tracks and monitors existing approaches to tuition in music performance within an Australian Conservatorium, where a range of performance specialisations is available in the areas of strings, keyboard, voice, woodwind, brass, percussion and jazz instruments. Framed by the pedagogical intentions, expectations and aspirations of teachers and students within this institution, the study generates a qualitative characterisation, based on a quantitative analysis, of pedagogical practices in a sample of one-to-one teaching practice. In this way, it attempts to identify the specific practices that express 'aspirational pedagogy'.

Although this research engages closely with the need to optimise effectiveness in one-to-one teaching (and to justify this effectiveness to parent institutions and other stakeholders), its intention is not to evaluate one-to-one teaching, but rather to identify, characterise and map observed pedagogical practices (Carey, Lebler \& Gall, 2012).

\section{Rationale}

The research arises from:

(1) the need to better understand the usefulness and effectiveness of one-to-one pedagogy, and to provide evidence-based accounts of its effectiveness;

(2) the need for music institutions to be accountable to their parent universities, government, and funding bodies, particularly given the high cost of individual tuition and the current rising funding pressures on universities internationally, 
which are serving to instigate a raft of reforms and reviews in tertiary music education, nationally and internationally;

(3) the escalating need for transparency in pedagogical practices in one-to-one settings in conservatoires, practices which remain largely unknown and unexplored, a situation compounded by the fact that one-to-one takes place behind closed doors in a culture of concealment;

(4) the need for ways to address the professional isolation and deprivatisation of one-to-one instrumental and vocal pedagogy (Triantafyllaki, 2010), for example by sharing conversations among teachers about their teaching practices;

(5) the need to improve the practice of one-to-one pedagogy by developing exemplary models for instrumental and vocal teaching and the concomitant need to continually improve teaching and mentoring skills among teachers (Burwell, 2005; Gaunt, 2008; Gaunt, Creech, Long \& Hallam, 2012).

\section{Descriptive scheme}

This research employs a descriptive scheme developed by Taylor and colleagues (Taylor, 2011; Taylor et al, 2012) to identify the nature and qualities of specific pedagogical practices in one-to-one teaching. Given the above rationale, the scheme provides an evidenced-based way to characterise those practices through analysis of videographic data of one-to-one pedagogical practices. It reflects the following principles:

- it focuses on what is important to student learning;

- it draws on a relational understanding of practices, focusing on interactions;

- it characterises only those aspects of one-to-one teaching that are visible, interpretable, and largely able to be altered or controlled by the teacher;

- it helps make the nature and quality of pedagogical practices visible, including to teachers themselves, thereby potentially promoting professional growth;

- and it is operationally practical.

The quantitative data generated through this study formed the basis for the qualitative characterisation of one-to-one pedagogy presented later in this paper. The approach to developing the scheme itself is detailed in Carey et al (in press).

\section{Method}

Out of 20 staff at the institution in question who volunteered to participate in this study, six were ultimately selected to participate, under the criteria of creating a representative sample of performance specialisms, full-time and part-time teachers, and gender balance. Each teacher-participant was asked to select two undergraduate students - one enrolled in the first year of tertiary music study and one in a more advanced year, to enable comparison of pedagogical approach across these groups. The students also represented a balance of gender within their cohort. Like most undergraduate performance students within this conservatoire, these students attend a weekly one-hour individual lesson, with only teacher and student present. Over the course of one semester, teacher-participants then self-recorded a series of lessons with each of their two chosen students, resulting in a total of over 78 hours of videographic material.

This raw data was then coded and analysed according to the descriptive scheme referred to above. Two researchers were involved in the coding, and double-coded a proportion of the videos to maximise reliability of characterisation. Further technical aspects of the scheme, including the characterisations themselves, attributes, and descriptors, are detailed in Taylor et al (submitted for review). 


\section{Statistical procedures}

Selected variables from the resulting 74 lesson characterisation records were factor analysed using a principal components analysis (PCA) approach (Jolliffe, 2002), in order to reduce the observed variables into a smaller set of important composite variables. Variables to be included in the PCA analysis were initially selected according to theoretical criteria, and were then screened for factorability - that is, ensuring that the sample size is large enough, that statistical relationships exist between items, and that these relationships are reliable and interpretable.

While the sample size was small for factor analysis, the data showed evidence of being highly factorable. All of the 22 chosen ordinal items correlated at least .3 with at least one other item, suggesting reasonable factorability. The Kaiser-Meyer-Olkin measure of sampling adequacy was above the recommended value of .6 at .79, the item communalities were all above .3 , and Bartlett's test of sphericity was significant $\left(\chi^{2}\right.$ $(231)=1476.693, p<.05)$. Given these initial indications of factorability, the analysis was therefore undertaken with all 22 items.

\section{Findings}

The aim of the principal components analysis was to reduce the 22 variables to a smaller number of factors, to concisely describe the relationships among the items. Two factors emerged from the analysis, when the eigenvalue $>1$ criterion was applied, and the same number of factors emerged using a scree plot test. The first factor explained $50.69 \%$ of the variance, and the second factor explained $8.89 \%$ of the variance. Oblique and orthogonal rotations, which are routinely conducted to maximise high correlations and minimise low ones and thus increase interpretability of the findings, yielded similar results to one another. The two identified factors were correlated at -.25 , a moderate negative statistical relationship.

At this stage a total of four items were removed because they did not load onto factors 1 or 2 above .4. The factor loading matrix for the final solution is presented in Table 1. The factor loading matrix shows the factor loadings and the communalities. The factor loadings indicate to what extent each of the original items is related to the overall composite factor variables, and the communality scores indicate how much variance in each variable is explained by both factors. Put another way, the communality is an indicator of how reliable an item is.

Table 1. Factor loadings and communalities based on a principle components analysis with oblique rotation for 18 items characterising one-to-one pedagogy $(\mathrm{N}=74)$

\begin{tabular}{|l|l|l|l|}
\hline & $\begin{array}{c}\text { Factor 1. } \\
\text { Transformative } \\
\text { pedagogy }\end{array}$ & $\begin{array}{c}\text { Factor 2. } \\
\text { Transfer } \\
\text { pedagogy }\end{array}$ & Communality \\
\hline Purpose of practice & .86 & .69 \\
\hline Approach to meaning making & .85 & .81 \\
\hline Pedagogical agility & .84 & .86 \\
\hline Teacher support for learning & .83 & .81 \\
\hline Progression between lessons & .80 & .78 \\
\hline
\end{tabular}




\begin{tabular}{|l|l|l|l|}
\hline Approach to diagnosis & .76 & & .75 \\
\hline Developing response to tasks & .61 & & .80 \\
\hline Concern for excellence & .72 & .77 \\
\hline Open or closed exploration of ideas & .71 & & .77 \\
\hline Reciprocity & .64 & .69 \\
\hline Approach to knowledge building & .61 & & .71 \\
\hline Teacher feed-forward & .51 & & .85 \\
\hline Open or closed exploration of & .42 & & .70 \\
\hline performance & & .75 & .65 \\
\hline Orientation to assessment & & .58 & .73 \\
\hline Explicit scaffolding of engagement & & -.75 & .81 \\
\hline Re-engaging prior curriculum & & -.61 & .51 \\
\hline Structuring of student engagement & & & .57 \\
\hline Note making by teacher & & & .73 \\
\hline Who initiates & & & .48 \\
\hline Framing of post-lesson tasks & & & \\
\hline
\end{tabular}

Note. Loadings of $<.3$ are suppressed.

Internal consistency for each of the two scales (an indication of how reliable the scale is - that is, the extent to which the items in each scale were scored similarly to one another, and therefore can be argued to be measuring the same construct) was examined using Cronbach's alpha. The alphas were acceptable to excellent, at .95 for Transformative Pedagogy (13 items) and .70 for Transfer Pedagogy (4 items).

\section{Pedagogical styles}

Factor analysis revealed two key types of pedagogical approach among the teacherparticipants. Type 1: Transformative pedagogy places emphasis on a depth of student understanding and ownership. It is characterised by a 'deep' approach to learning orientation on behalf of the teacher, and pedagogical agility in terms of its collaborative, explorative, scaffolded, meaningful, and contextualising qualities. In this type of teaching, the learning outcomes for the student are transformative. The approach is open and exploratory, with deep learning and an emphasis on sense-making and contextualising content (including content for assessment) within the learner's experience. Transformative-style teachers are able to promote both performance and 
learning outcomes in their students, though the primary goals are in terms of learning (increasing ability through new knowledge or skills), not performance (with its aim to validate one's ability or avoid demonstrating a lack of ability) (Grant \& Dweck, 2003).

Type 2: Transfer pedagogy contrasts with transformative pedagogy in that the approach is largely didactic. It is characterised by instruction, scaffolding that promotes mimicry, less flexibility, orientation towards assessment, and decontextualized learning. Its objective is 'defined' excellence versus the 'expansive' excellence of transformative learning. Teachers who tend towards this approach are more assessment-oriented than learning-oriented. Learning is only minimally scaffolded, and tends to be more decontextualized than transformative learning. Although teachers expressed a desire to foster independent learning abilities in their students, the development of technical and musical skills dominated their practice. Like Type 1 (Transformative) teachers, transferstyle teachers may produce both performative and learning outcomes in their students, but with much greater emphasis on the former; thus, learning outcomes are more confined/focused than expansive.

\section{Characterisation of teacher-participants}

Unweighted indexes running from 0 to 1 based on the two pedagogical style factors were produced, and teachers were compared based on these indexes. All of the teachers exhibited characteristics of both teaching styles, but generally the teachers who participated in this study tended to adopt a Type 2 (Transfer) style, characterised by a definite and determined notion of excellence, an orientation towards assessment as an end point, and a predefined approach to pedagogy. This predefined approach included general verbal scaffolding of engagement along with clear directions relating to specific tasks, and modelling or demonstration. A smaller number of teachers adopted a Type 1 (Transformative) style, characterised by a deep, sense-making and collaborative approach to pedagogy, an emphasis on contextualization of learning within the student's broader life and career, and agility in pedagogical choices (see Figure 1).

Figure 1. Pedagogic styles of study participant teachers.

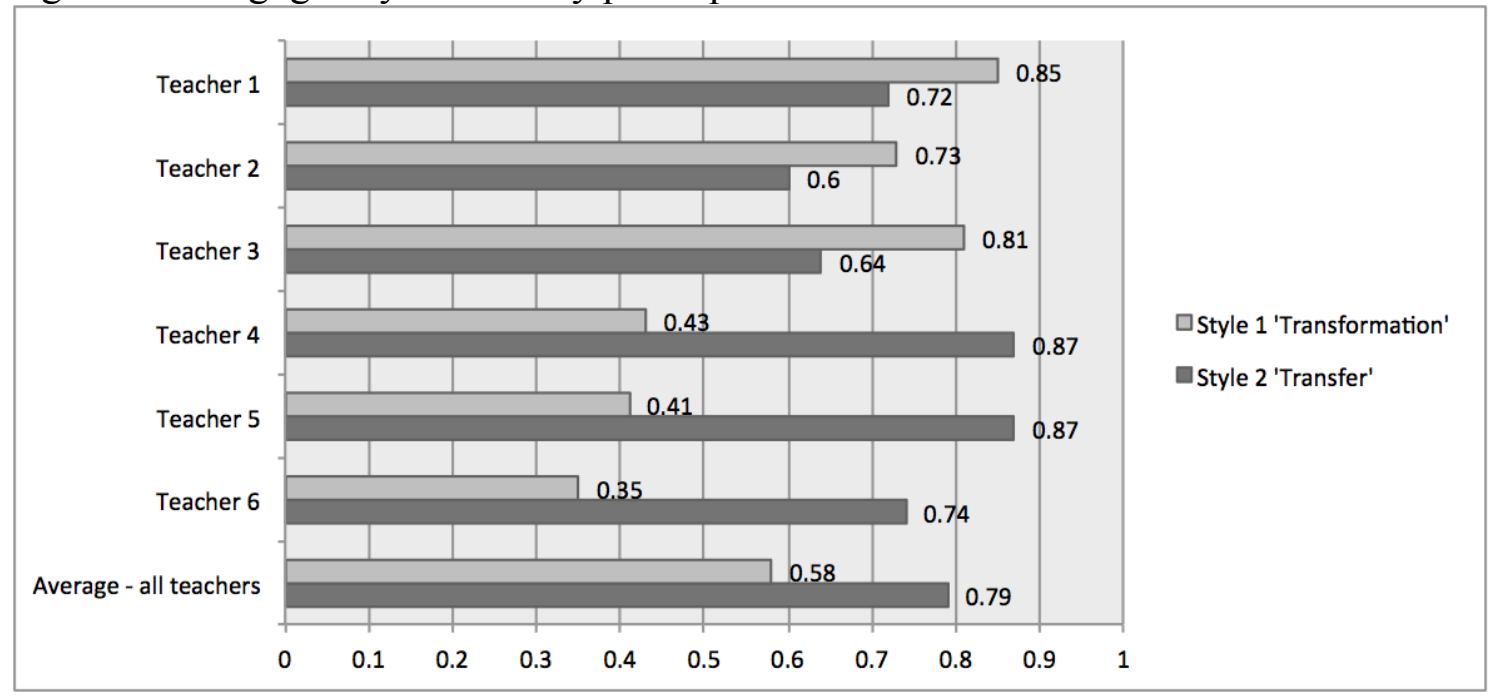

\section{Early versus advanced students}

Findings revealed differences in pedagogical approach to first-year versus more advanced students. Those teachers predominantly falling into Type 1 (Transformative) 
generally tended to exhibit more transformative characteristics when teaching advanced (third or final year) students than with early (first or second year) students; that is, they heightened their 'transformative' behaviours as students progressed $(F(1,33)=12.34$, $\mathrm{p}<.001)$. Their use of transfer teaching styles remained low whether they were teaching early or advanced students $(\mathrm{F}(1,33)=1.43, \mathrm{p}>0.5)$. Type 1 teachers adopted more reciprocal, open and exploratory teaching styles with advanced students than with early students ('Reciprocity' $-\mathrm{t}(33)=3.91, \mathrm{p}<.001$; 'Open exploration of ideas' $-\mathrm{t}(33)=$ $6.91, \mathrm{p}<.0001$, 'Open exploration of performance' $-\mathrm{t}(33)=4.57, \mathrm{p}<.001)$. They spent progressively more emphasis on placing practice into a context of consolidating existing student knowledge, as opposed to 'getting it right' ('Purpose of practice' $-\mathrm{t}(33)=3.65$, $\mathrm{p}<.001$. Type 1 teachers also placed greater emphasis on personal and artistic development as students became more advanced ('Concern for Excellence' - $t(33)=$ $3.04, \mathrm{p}<.01$ ). Type 2 (Transfer) teachers displayed more characteristics of transformative teaching in lessons with more advanced students $(F(1,25)=6.54, p<.05)$, and also displayed more characteristics of transfer teaching with advanced than early students $(\mathrm{F}(1,27)=17.34, \mathrm{p}<.001)$. Like Type 1 teachers, type 2 teachers placed greater emphasis on personal and artistic development as students became more advanced ('Concern for Excellence' - $\mathrm{t}(31)=-5.04, \mathrm{p}<.001$ ). Type 2 teachers provided more developmental support to advanced students ('Support for Learning' $-\mathrm{t}(31)=-3.39$, $\mathrm{p}<.01$ ), although the actual level of support remained consistently lower than that provided by Type 1 teachers. Type 2 teachers provided progressively less scaffolding of engagement of as students progressed ('Scaffolding of Engagement' $-\mathrm{t}(31)=2.31$, $\mathrm{p}<.05)$. Advanced students of Type 2 teachers tended to be required to take more notes than early students of Type 2 teachers ('Student Record Taking' $-\mathrm{t}(31)=-3.29, \mathrm{p}<.001$ ) Interestingly, for Type 2 teachers, the more advanced the student, the more closed the exploration of performance $(\mathrm{t}(31)=2.07, \mathrm{p}<.05)$, perhaps because Type 2 teachers tended to mainly focus on performance outcomes through mimicry. In these circumstances, the risk is that students become disinclined to explore and collaborate in their own learning, and rather than attempting to change a didactic teaching approach, will tend to adapt to it.

\section{Discussion}

The two pedagogical approaches identified in this study resonate with those explicated in constructivist alignment literature, where the distinction is made between teaching facts and information (leading to surface learning and 'declarative knowledge' sufficient to pass a course) and deep, transformational teaching that aligns authentic learning activities, assessment, and learning outcomes (Biggs, 2003, 2008).

Constructivist alignment theory suggests that students are likely to be more actively engaged in their learning if taught in a transformative way, one which emphases process over content.

That said, the question of which pedagogical style - transformative or transfer produces the best technical or musical results in students was outside the scope of this study: the focus here was on characterising, rather than evaluating, one-to-one. The relative pedagogical effectiveness of each approach in the one-to-one conservatoire environment is a topic ripe for further research (though the constructivist alignment literature would predict that the transformative approach may be more desirable in terms of 'deep' learning). Those teachers who exhibit transformative qualities in their teaching are (by definition) maximising the student experience in terms of process and performance outcomes, rather than performance outcomes alone. The findings of the study therefore corroborate the tenet that performance outcomes are not the sole 
measure of the effectiveness of teaching: that 'the process of instruction - the interaction between teacher and student or the effect of teacher behaviour on the student - is as important as its product' (Kurkil, 2007, p. 330).

In this way, by focusing on process as well as performance outcomes, 'transformative' teachers tend to foster in their students an adaptive and flexible approach to learning, a resilience that may stand those students in good stead for dealing with work-related (and other) challenges they may face after they complete formal study, and the creative entrepreneurship skills that are increasingly necessary for building a successful career in the arts (Bridgstock, 2012). By its nature, 'transformative' teaching also increases the potential for one-to-one tuition to serve a mentoring function, with teachers helping students realise their career aspirations and making the transition to professional life as a musician (Gaunt, Creech, Long \& Hallam, 2012). At a time when universities are 'prepar[ing] graduates for careers not yet imagined' and when students are likely to engage in 'a lifetime of specialised work requiring multiple advanced skill sets in which they will continually learn and re-learn skills for performance in roles that may not have been invented yet', (Bridgstock \& Hearn, 2012, p. 108), higher-order transformative learning as opposed to surface-level 'declarative' knowledge seems indispensable.

Conversely, when teachers approach their students' learning in a didactic way, providing content and instruction in a Type 2 (Transfer) style, students may become accustomed to (dependent upon) this approach. In itself, this is not necessarily disadvantageous to student learning, and may in fact suit some students. However, when this dependency is non-contested by the students (as is often the case; see Carey and Grant, under review), the teacher may fail to explore pedagogical alternatives, which in turn may lead to a stagnation of pedagogic agility. As the teacher's agility shuts down there is potential for student's agility to do so too. Distinguishing between 'performance goals' and 'learning goals' (characterised respectively by transfer- and transformativestyle pedagogy), Grant and Dweck (2003) found evidence that:

learning goals do exert a positive influence on both intrinsic motivation and performance when individuals encounter prolonged challenge or setbacks. In addition, although performance goals that are focused on validating ability can have beneficial effects on performance when individuals are meeting with success, these same goals can predict impaired motivation and performance after setbacks. (2003, p. 552)

For these reasons, students taught in a predominantly 'transfer' style may be less prepared for a diverse career and less resilient when faced with career challenges or crises after their tertiary studies than those students who have experienced transformative teaching. This is a potential area for further investigation.

The findings of this research are highly consistent with those emerging from related qualitative studies at the institution in question, as part of a wider enquiry into one-to-one teaching using a triangulated multi-method approach (Carey et al, in press). The perspectives and experiences of students revealed through focus groups in this study suggests that students also experience teaching as predominantly Type 1 (Transformative) or Type 2 (Transfer). Those students taught in a predominantly transformative style feel mentored as musician, performer, and even as a person, while those taught by transfer feel mentored as performers only. While some studentparticipants expressed preference for transfer-style pedagogy, the majority preferred transformative teaching. Some students experiencing a transfer-style approach to 
teaching spoke of their 'loss of energy' and a sense of lacking ownership of their learning (Carey and Grant, under review).

Qualitative data from semi-structured interviews with one-to-one teachers, both those who participated in this present study (Carey and Grant, under review) and those interviewed for other research projects (e.g. Nerland, 2007), corroborate the findings that these teachers display tendencies towards transformative or transfer pedagogy. The following comment from a teacher to his student in a study by Nerland, for example, shows evidence of the performance- and outcomes-focussed transfer style:

You must not think in ways like 'Now I have been very clever. I have been practicing a lot'. The truth is that if it does not give results, then you are nothing (laughs at his own expression). (Video transcript). (cited in Nerland, 2007, p. 405)

By contrast, another teacher who participated in the Nerland study exemplified transformative pedagogical strategies that sought to foster self-determination and personal growth in his students (2007, p. 411):

Mostly, I am concerned that they have a chance to grow as human beings and to develop their personality. And to realize their potential. And not that all should sound exactly the same ... way[,] that's not important for me, I would rather that they should act as individual human beings. (cited in Nerland, 2007, p. 409)

\section{Recommendations}

In terms of recommendations relating to the immediate institutional context in which this study was conducted, the most self-evident is that of professional development and growth, particularly for those teachers exhibiting primarily a 'transfer' style of teaching. To this end, each of the teacher-participants in this study was provided with an individual report summarising and interpreting the most important findings about their pedagogic strengths, as well as suggesting some areas where development could be beneficial. All teacher-participants were given the opportunity to discuss in private these results with members of the research team. At an individual level, it was recommended that teachers continue to self-record video lessons for their own reflective learning, equipped with a clearer understanding of the characteristics of transfer and transformative pedagogy, and the specific behaviours that characterise each type (enumerated in the descriptive scheme).

At an institutional level, it is recommended that professional development initiatives for teachers focus on those areas that indicate the most opportunity for making pedagogical practices more transformative. These were:

- Purpose of practice - using practice effectively as an opportunity for consolidation and application rather than 'getting it right';

- Pedagogical agility - exploration of different pedagogic approaches in response to different situations and needs - building a responsive instructional 'toolkit';

- Approach to diagnosis - building a collaborative approach to identifying and solving problems through which both student and teacher learn; and

- Approach to meaning-making - taking a collaborative approach to building knowledge in which shared meanings can be discussed and elaborated rather than simply teacher specified.

\section{In conclusion}


The purpose of this work is 'to gain more insight into the variety of teaching practices carried out [in one-to-one music teaching], as well as into the mechanisms through which they come into being' (Nerland, 2007, p. 413). This study represents an innovative and systematic attempt to achieve these, by structuring a reflective exploration of how teaching might become more effective. These intentions, and the progress towards them, have global resonance, as well as a political value within an Australian higher education sector for which public financial support demands greater attention to the quality of the educational services provided within higher education institutions. For these reasons, the authors hope this pilot study will be replicated at other institutions, to broaden the data set, to verify the descriptive scheme, and eventually to enable comparison and triangulation across contexts.

\section{References}

Association of European Conservatoires (2010). Quality assurance and accreditation in higher music education. Amsterdam: Association of European Conservatoires.

Biggs, J. (2003). Teaching for quality learning at university: What the student does (2nd ed), (Berkshire, SRHE \& Open University Press).

Biggs, J. B. (2008). Constructive Alignment. Retrieved October 21, 2012, from http://www.johnbiggs.com.au/constructive_alignment.html

Bridgstock, R. (2012). Not a dirty word: Arts entrepreneurship and higher education, Arts and Humanities in Higher Education. http://ahh.sagepub.com/content/early/2012/11/20/1474022212465725

Bridgstock, R. \& Hearn, G. (2012). A conceptual model of capability learning for the 21 st century Knowledge Economy, in: D. Rooney, G. Hearn \& A. Ninan (Eds) Handbook on the Knowledge Economy (Cheltenham, Edward Elgar), 105-119.

Burwell, K. (2005). A degree of independence: Teachers' approaches to instrumental tuition in a university college. British Journal of Music Education, 22(3), 199-215.

Carey, G. (2008). New understanding of 'relevant' keyboard pedagogy in tertiary institutions (Saarbrucken, Germany, Verlag Dr. Muller).

Carey, G. (2010, 27-30 July). Too much performing, too little learning? Reflections on pedagogical practices within the Conservatoire, paper presented at the $18^{\text {th }}$ International Seminar of the Commission for the Education of the Professional Musician (CEPROM) (Nedlands, Western Australia, International Society for Music Education).

Carey, G. \& Lebler, D. (2012). Reforming a Bachelor of Music program. International Journal of Music Education. Online pre-print published 25 September 2005. doi: $10.1177 / 0255761412459160$

Carey, G., Lebler, D. \& Gall, S. (2012). Investigating the one-to-one teaching model in higher music education: Developing a collaborative model of inquiry, Scientia Paedagogica Experimentali:International Journal of Experimental Research in Education, 47(2), 175-198.

Carey, G., \& Grant, C. (under review). Teacher and student perspectives on one-to-one pedagogy: Practices and possibilities. 
Carey, G., Grant, C., McWilliam, E., \& Taylor, P. (in press). One-to-one pedagogy: Developing a protocol for illuminating the nature of teaching in the conservatoire. International Journal for Music Education. Manuscript accepted 20 February, 2013.

Chronister, R. (2005). Principles of teaching and learning, in: Chronister, R. \& Darling, E., $A$ piano teacher's legacy: Selected writings by Richard Chronister (Kingston, NJ, Frances Clark Center for Keyboard Pedagogy), 7-28.

Froehlich, H. (2002). Thoughts on schools of music and colleges of education as places of 'rites and rituals': Consequences for research on practising. In I. M. Hanken, S. G. Nielsen, \& M. Nerland (Eds), Research in and for Higher Music Education (pp. 149-165). Oslo: Norges Musikkhogskole.

Gaunt, H. (2007). One-to-one tuition in a conservatoire: The perceptions of instrumental and vocal teachers. Psychology of Music 36(2), 215-245.

Gaunt, H. (2009). One-to-one tuition in a conservatoire: The perceptions of instrumental and vocal students. Psychology of Music 38(2), 178-208.

Gaunt, H., Creech, A., Long, M., \& Hallam, S. (2012). Supporting conservatoire students towards professional integration: One-to-one tuition and the potential of mentoring. Music Education Research, 14(1), 25-43.

Grant, H. \& Dweck, C. (2003) Clarifying achievement goals and their impact, Journal of Personality and Social Psychology, 85(3), 541-553.

Harrison, S. (1997). Submission to the review of higher education financing and policy. Review of Higher Education Financing and Policy - Submissions. Retrieved August 9, 2012, from http://www.pc.gov.au/ic/research/submission/highered/

Harrison, S. D. (2004). Lifelong learning in music education: A brief examination. In D.

Roebuck, J. Searle \& C. McKavanagh (Eds.), Doing, thinking, activity, learning: Proceedings of the 12th Annual International Conference on Post-compulsory Education and Training 1, 204-208. Brisbane: Australian Academic Press.

Jolliffe, I. (2002). Principal component analysis. New York: Springer-Verlag.

Kennell, R. (1997). Teaching music one on one: A case study. Dialogue in Instrumental Music Education, 21(1), 69-81.

Lennon, M. \& Reed, G. (2012). Instrumental and vocal teacher education: Competences, roles and curricula. Music Education Research, 14(3), 285-308.

Lockett, D. R. (2007). The scholar/performer: A new dimension in music research. Proceedings of the $8^{\text {th }}$ Australasian Piano Pedagogy Conference, 2-6 July 2007. Canberra: Australian National University. Retrieved 12 July, 2012, from http://www.appca.com.au/2007proceedings.php

Merson, F. (2012, July). Enraged students jam against ANU School of Music cuts. Limelight Magazine, 13.

Mills, J. (2002). Conservatoire students' perceptions of the characteristics of effective instrumental and vocal tuition. Bulletin of the Council for Research in Music Education, $153 / 154,78-82$. 
Nerland, M. (2007) One-to-one teaching as cultural practice: two case studies from an academy of music, Music Education Research, 9(3), 399-416.

Perkins, R. (2013). Learning cultures and the conservatoire: An ethnographically-informed case study. Music Education Research, 15(2), 196-213.

Persson, R. (1994). Concert musicians as teachers: On good intentions falling short. European Journal for High Ability 5, 79-91.

Persson, R. (1996). Brilliant performers as teachers: A case study of commonsense teaching in a conservatoire setting. International Journal of Music Education, 28, 25-36.

Presland, C. (2005). Conservatoire student and instrumental professor: The student perspective on a complex relationship. British Journal of Music Education, 22(3), 237-248.

Schmidt, C. P. (1989). Individual differences in perception of applied music teaching feedback. Psychology of Music, 17(2), 110-112.

Taylor, P.G. (2012). BGS Tablet Pedagogical Practices project: Final report. Unpublished report (Brisbane, Australia, Brisbane Grammar School).

Taylor, P.G., Kwek, D., Tan, C. \& Short, B. (2012). Coding of classroom pedagogical practices: An international comparison.

\section{Author biographical notes}

Gemma Carey is Senior Lecturer in Piano and Head of Pedagogy at the Queensland Conservatorium Griffith University. Gemma's expertise and research interests are in the area of Performance Pedagogy, Curriculum and Teaching and Learning. She has presented and published papers in the field of Instrumental Pedagogy nationally and internationally, and works with students from pre-tertiary to doctoral level.

Ruth Bridgstock is a research fellow in the Creative Workforce Program of the Australian Research Council Centre of Excellence in Creative Industries and Innovation at Queensland University of Technology. She co-ordinates the Bachelor of Creative Industries core program, which aims to develop innovation and entrepreneurship capabilities in students of creative courses. Ruth's work is concerned with describing the capabilities needed for successful careers in the creative industries, and developing higher education programs to build those capabilities.

Peter Taylor is an Adjunct Professor at Griffith University (Australia), having recently worked as a Professor in the Centre for Research in Pedagogy and Practice at Singapore's National Institute of Education. His most recent research has given rise to methodology for characterising pedagogical practices across a range of national and international sites and systems.

Erica McWilliam is an Adjunct Professor in the Centre of Excellence for Creative Industries and Innovation in the Creative Industries Faculty of the Queensland University of Technology. She has a prolific record of publication in teaching and learning across all sectors of education, from early childhood to doctoral studies, and is a Fellow of the Australian College of Educators and an Associate Fellow of the Australian Learning and Teaching Council.

Catherine Grant is Research Fellow at the Queensland Conservatorium Research Centre, Griffith University. Her research interests lie in the areas of tertiary music teaching and learning, performing arts healthcare, and music sustainability. 